\title{
Trends and Solutions for Future Steel Grade Development
}

\author{
Axel Rimnac ${ }^{1, a^{*}}$ and Thomas Pfatschbacher ${ }^{1, b}$ \\ ${ }^{1}$ Primetals Technologies Austria GmbH, Turmstrasse 44, 4031 Linz, Austria \\ aaxel.rimnac@primetals.com, bthomas.pfatschbacher@primetals.com
}

Keywords: quality, lean product development, cost efficiency, physical simulator use, numerical simulation.

\begin{abstract}
The world steel market is in a phase of maturity. Worldwide growth in steel demand is expected to be in the range of $1 \%$ per year and the world's biggest market, China, is facing a phase of stagnating or even diminishing steel demand. The situation has changed from a supplier driven to a customer driven market meaning that customer demands are increasing and margins are dropping. Besides increasing levels of digitization and service orientation as well as the development of new sales channels the delivery of higher quality, introduction of new steel grades and further customization of high-end products to cover niche markets are of prime importance to keep or increase market shares. Besides efficient organization and execution of the daily business ranging from production to quality management and customer services paired with data-based insight, highly efficient research and development (R\&D) with increasingly limited amount of resources is a must. This paper addresses the latter topic regarding trends for future steel grade demands and strategies for efficient R\&D.
\end{abstract}

\section{Introduction}

Competition on the global steel market is fierce. For more than a decade the world has exhibited an average utilization of steel making facilities around $85 \%$ and an annual growth rate around $1 \%$ [1] which is also the forecast for the coming years [2]. There is no reason to assume that the steel industry is going to witness substantially higher growth in the next years as growth rates of the past years were caused by the restructuring of Europe after world war II and the China boom in the years 1995 until 2013 [4]. Put in a more general framework, steel market growth in the past were caused by economic development and population growth. China for example, has more or less closed the gap to the western world in terms of economic development causing nearly a doubling of global steel demand between 2000 and 2013 and overtaking the US as the biggest economy worldwide in 2017 [6]. Although China is by far the biggest market for the worldwide steel industry, it experienced the first drop in steel demand in the years 2014-2016 since 1995 indicating market saturation. The same is indicated by the drop in $\operatorname{ROCE}^{1}$ from $20-24 \%$ for steelmaking and distribution in 2007 to $3 \%$ in 2013 and 2014 [1]. Consequently, as the growth of the worldwide population is forecasted to lie between $1-2 \%$ annually [4], total steel consumption will, at most, grow moderately. This is accompanied by a general trend towards quality, customers do not only require steel grades according to e.g., Chinese, ASTM, EN or JIS based standard specifications, demand is going far beyond in both, tightness of mechanical or geometrical property tolerances, formability and surface quality.

In addition, the automotive industry which has traditionally been a driver for innovations in the metals industry is under severe pressure from governments worldwide to lower fuel consumptions to an equivalent of 54.5 miles per gallon (mpg) by 2025 because of corresponding emissions regulations by simultaneously fulfilling increasing safety requirements [7] in the US. Similar legal regulations are enforced in Europe and are in preparation for China according to government announcements [9]. As a consequence, OEMs push suppliers towards development of higher strength grades at no or at most moderate cost increases as well as steels for electrical drives [10]

\footnotetext{
${ }^{1}$ ROCE $=$ EBIT/capital employed.
} 
and try to use lightweight materials such as aluminium, polycarbonates or carbon composites and even magnesium [9] if feasible from a utility/cost point of view [8].

Therefore, leading consulting companies and analysts predict harsh competition in the steel market [3] and start to publish advice on compulsive action fields to sustain in the market and foster further growth. This includes efforts to improve steel characteristics, i.e., fulfil material requirements within tighter tolerances by using less tonnages as well as improvements in understanding materials behaviour and new ways of manufacturing. Besides this, digital disruption is identified as a must for increase of operational efficiency, optimization of ROCE, implementation of new sales channels and tighter interactions between supplier and customer [5].

The implications on both, daily operations as well as development of new and optimization of known steel grades already produced, range from the respective process designs to the corresponding structure and interaction of research and development (R\&D), production and quality-control departments. The efficient use of production facilities for $\mathrm{R} \& \mathrm{D}$, offline development, minimum risk of unscheduled downtime losses and proper Know-How build up and management are key ingredients to streamline $R \& D$ activities towards short time to market at minimum costs.

\section{Trends in Future Steel Grade Demand}

The general trend in steel grade demand is towards higher strength, tighter mechanical and geometrical tolerances and higher surface quality, regardless of the specific sector to be supplied. In terms of market share per sector it is expected that steel consumption for the automotive industry will rise by around $1.6 \%$ per year until 2035 and for the ship building industry stagnation until 2025 is forecasted with moderate growth afterwards [18]. For China it is to be expected that the market share of steel for the construction industry which was around 68\% in 2017 (see Fig. 1) will develop towards a similar level as reported for Europe.

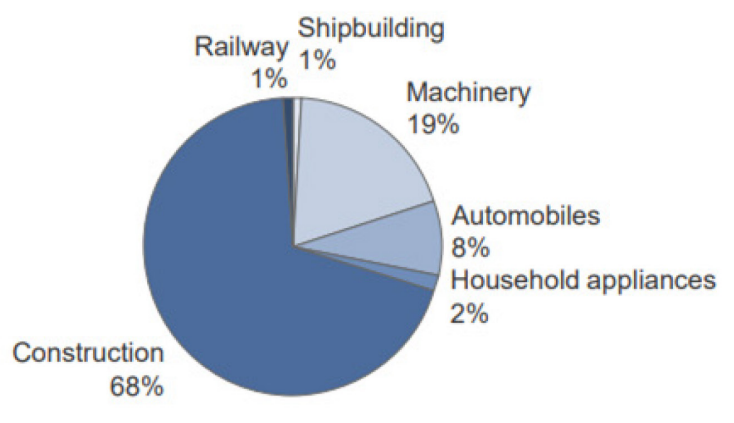

Fig. 1: Steel demand by sectors in 2017. Left: China, right: Europe [12].

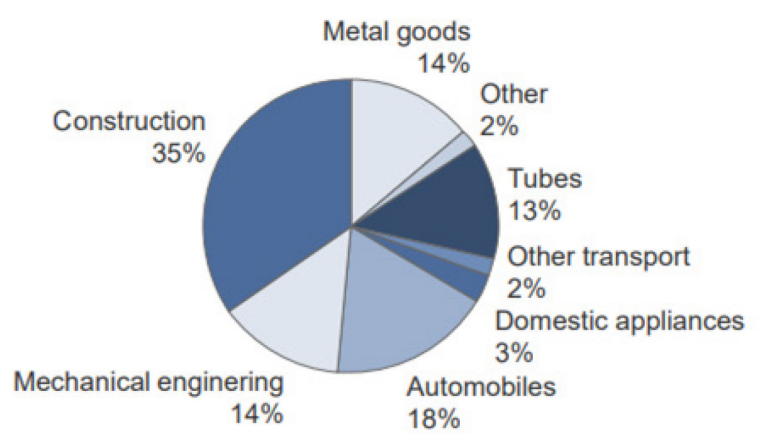

Therefore, higher quality and value-added products for e.g., engineering applications and the automotive industry will gain importance. Moreover, in order to compensate for missing growth opportunities in the home market, the export of higher value-added and speciality steel (which is encouraged by the Chinese government) will remain one of the few options for growth or even survival [19].

Although demands in quality requirements, innovation capabilities, market power and capabilities in root-cause analysis and failure resolution are high, the market niche with highest value-add prospective is the automotive industry. Therefore, entering and sustaining in this field necessitates not only a reasonable cost-basis but also deep Know-How in the production of demanding steel grades including seamless documentation of all process steps and the capability for fast detection of error sources and the identification of mitigation means.

Advanced high strength steels (AHSS) are the key ingredient in recent car designs taking a share of about 60\% [11]. From 2007 to 2013 the amount of mild steels used in body and closure of new 
cars developed dropped from 58 to $47 \%$ while the use of bake-hardening (BH) and high-strength steels (HSS) has increased from 33 to 39\% and the use of AHSS (both, dual-phase (DP) and non-DP type) have increased from 9 to $14 \%$ [17]. This trend is underlined by the ultra-high strength steel (UHSS) automotive program of Arcelor-Mittal pushing strongly for an upgrade in companycapabilities to supply coated value-added grades in the Giga - Pascal range [20] to support the development of even leaner light - weight constructions for individual transportation. The same is reported from POSCO [19].

In view of lightweight design the possible levers for weight reduction are volume (i.e, thickness and/or surface) reduction of parts and density reductions while maintaining strength levels [9] meaning either going for composite materials, density reduced steels, light metals or increasing strength levels. The latter is tempting as stability of a body part scales linearly with thickness, i.e., the stronger the material the thinner the gauge to take the same load. However, this scaling is not the case for e.g., bending or torsion resistance of flat parts meaning that either strength has to increase super linear with thickness reduction and/or stiffness has to be improved by designing parts that need to stand high strains without failure during their forming process. However, especially for crash relevant part, the ability to absorb energy in case of a crash must be taken care of. This means for relevant materials that the ECO-index, i.e., the product of tensile strength and elongation has to be significantly higher compared to conventional products which exhibit an ECO-index of about $10 \mathrm{GPa} \%$ towards $20 \mathrm{GPa} \%$ for quenched and partitioned (Q\&P) steels [14]. This is also reflected in the availability of steel grades assumed for the future steel vehicle as displayed in Fig. 2, which, besides AHSS grades also includes the class of press-hardening steels (PHS) that combine high formability in the hot state with high strength in the as - quenched final shape at room temperature.

As both, revenue and costs for AHSS and UHSS type steel production is high, possibilities to shorten the processing routes are intensely investigated as shorter routes mean less costs and, hence, higher margins. One prime example of these approaches are the activities taking place around thin slab casting and rolling facilities operated in endless mode [24][25].

\section{Development, Production and Quality Control}

Unfortunately the undisputable advantages of these grades in applications are bought at the cost of some still challenging issues, for instance delayed fracture, coating topics and forming issues. This implies that the variety of steel grades necessary inside the family of AHSS and UHSS grades will increase significantly.

As the production of AHSS (both, conventional and $3^{\text {rd }}$ generation types) and UHSS grades needs very tight processing windows, detailed Know-How on processing parameters, sensitivities, i.e., the impact of variations in processing parameters on final product properties need to be known in order to arrive at the dedicated special design of rolling and heating/cooling schedules which are necessary for reliable AHSS production [15].

Moreover, the identification of the so - called controls according to the automotive standard TS16949, i.e., processing parameters indicating final product quality has to be done to generate a profound measure for reliability and compliance to specification of the material delivered. This information has to be provided by a properly designed approach to product development. Because of the vast number of important processing parameters for advanced grades complete testing by bruteforce methods is neither feasible in terms of search space size nor economically affordable. Therefore a clever combination of methods for the determination of all three ingredients, setup values for processing parameters, limits for acceptable variations of them and the identification of quality measures is necessary. 


\begin{tabular}{|c|c|c|c|c|c|c|c|c|c|c|}
\hline $\begin{array}{c}\text { Item } \\
\#\end{array}$ & Steel Grade & \multicolumn{2}{|c|}{ Thickness (mm) } & $\begin{array}{l}\text { Gauge } \\
\text { Length }\end{array}$ & $\begin{array}{c}\text { YS } \\
\text { (Mpa) } \\
\text { Min }\end{array}$ & $\begin{array}{c}\text { YS } \\
\text { (Mpa) } \\
\text { Typical }\end{array}$ & $\begin{array}{c}\text { UTS } \\
\text { (Mpa) } \\
\text { Min }\end{array}$ & $\begin{array}{c}\text { UTS } \\
\text { (Mpa) } \\
\text { Typical }\end{array}$ & $\begin{array}{c}\text { Tot EL } \\
(\%) \\
\text { Typical }\end{array}$ & $\begin{array}{l}\text { N-value } \\
\text { Typical }\end{array}$ \\
\hline 1 & Mild 140/270 & 0.6 & 2.3 & A50 & 140 & 150 & 270 & 300 & $38-44$ & 0.23 \\
\hline 2 & BH 210/340 & 0.64 & 2.79 & A50 & 210 & 230 & 340 & 350 & $35-41$ & 0.19 \\
\hline 3 & $\mathrm{BH} 260 / 370$ & 0.64 & 2.79 & A50 & 260 & & 370 & & $32-36$ & 0.17 \\
\hline 4 & IF $260 / 410$ & 0.6 & 2.3 & A50 & 260 & 280 & 410 & 420 & $34-48$ & 0.20 \\
\hline 5 & $\mathrm{BH} 280 / 400$ & 0.6 & 2.8 & A50 & 280 & 324 & 400 & 421 & $30-34$ & 0.16 \\
\hline 6 & IF 300/420 & 0.6 & 2.3 & A50 & 300 & & 420 & & $29-36$ & 0.20 \\
\hline 7 & DP 300500 & 0.5 & 2.5 & ABO & 300 & 345 & 500 & 520 & $30-34$ & 0.16 \\
\hline 8 & FB 330/450 & 1.8 & 3.0 & ABO & 330 & 380 & 450 & 490 & $29-33$ & 0.17 \\
\hline 9 & HSLA 350/450 & 0.5 & 3.0 & ABO & 350 & 360 & 450 & 470 & $23-27$ & 0.16 \\
\hline 10 & DP 350600 & 0.6 & 2.5 & ABO & 350 & 385 & 600 & 640 & $24-30$ & 0.19 \\
\hline 11 & TRIP 350/600 & 0.6 & 2.3 & A50 & 350 & 400 & 600 & 630 & $29-33$ & 0.20 \\
\hline 12 & DP 400/700 & 1.27 & 3.2 & & 400 & & 700 & & $19-25$ & 0.14 \\
\hline 13 & TRIP $400 / 700$ & 1.0 & 1.6 & & 400 & & 700 & & $24-28$ & \\
\hline 14 & HSLA 420 500 & 0.76 & 3.2 & & 420 & 430 & 500 & 530 & $22-26$ & \\
\hline 15 & FB 450/600 & 1.8 & 3.0 & ABO & 450 & 530 & 560 & 605 & $18-23$ & 0.11 \\
\hline 16 & TRIP 450/800 & 1.0 & 1.6 & ABO & 450 & 550 & 800 & 825 & $26-32$ & 0.24 \\
\hline 17 & TWIP 450/1000 & 1.2 & & A50M & 450 & 496 & 1000 & 1102 & $50-54$ & $0.41^{*}$ \\
\hline 18 & HSLA 490,600 & 0.75 & 3.2 & & 490 & 510 & 600 & 630 & $20-25$ & 0.13 \\
\hline 19 & CP 500800 & 0.8 & 1.6 & ABO & 500 & & 800 & & $10-14$ & \\
\hline 20 & DP 500800 & 0.6 & 2.3 & A50 & 500 & 520 & 800 & 835 & $14-20$ & 0.14 \\
\hline 21 & HSLA 550,650 & 0.75 & 3.2 & A50 & 550 & 586 & 650 & 676 & $19-23$ & 0.12 \\
\hline 22 & SF 570/640 & & & & 570 & & 640 & & $20-24$ & 0.08 \\
\hline 23 & SF $600 / 780$ & 2.9 & 5 & A50 & 600 & 650 & 780 & 830 & $20-24$ & \\
\hline 24 & DP 700/1000 & 0.6 & 2.3 & A50 & 700 & 720 & 1000 & 1030 & $12-17$ & 0.09 \\
\hline 25 & CP 800/1000 & 0.8 & 3.0 & A80 & 800 & 845 & 1000 & 1005 & $8-13$ & 0.11 \\
\hline 26 & MS 950/1200 & 1.5 & 3.2 & A50M & 950 & 960 & 1200 & 1250 & $5-7$ & 0.07 \\
\hline 27 & CP $1000 / 1200$ & 0.8 & 2.3 & & 1000 & 1020 & 1200 & 1230 & $8-10$ & \\
\hline \multirow[t]{3}{*}{28} & $\begin{array}{l}\mathrm{HF} 1050 / 1500 \\
(22 \mathrm{MnB} 5)\end{array}$ & & & & & & & & & \\
\hline & $\begin{array}{l}\text { Conventional } \\
\text { forming }\end{array}$ & 1.0 & 2.5 & ABO & 340 & 380 & 480 & 500 & $23-27$ & \\
\hline & $\begin{array}{l}\text { Heat treated } \\
\text { atter forming }\end{array}$ & 1.0 & 2.5 & $\mathrm{~A} B \mathrm{O}$ & 1050 & 1220 & 1500 & 1600 & $5-7$ & \\
\hline 29 & MS 1150/1400 & 0.5 & 1.5 & A50 & 1150 & 1200 & 1400 & 1420 & & \\
\hline 30 & MS 1250/1520 & 0.5 & 1.5 & A50M & 1250 & & 1520 & & $4-6$ & 0.07 \\
\hline
\end{tabular}

Fig. 2: Steel grades assumed to be available for the future steel vehicle (FSV) body [10].

\section{Optimized Routes in Steel Grade Development}

Although still some white spots exist in understanding the physical mechanisms governing material behaviour and sometimes structure - property relations do not seem to be straight forward, metallurgical modelling has reached a state of maturity permitting the determination of proper alloy designs and good starting parameters for the production of specific grades having high probability of matching mechanical property requirements. Irrespective of its predictive power and practicability as a means to generate ideas, a tool to sort thoughts and perform feasibility investigations, steel grade design purely based on modelling and numerical simulation is, in the general case, highly valuable but not yet sufficient for optimum preparation of large - scale production trials. In order to bridge $100 \%$ of the gap between model - based results and behaviour on the production unit selected small scale lab tests are a proper means. Despite the possibility to interrupt trial production at any intermediate step providing unparalleled insight compared to production facilities the smaller lot sizes necessary mean lower expenses for the preparation of trial alloys. Typical lot sizes are between less than $1 \mathrm{~kg}$ for e.g., Gleeble type machines to about $100 \mathrm{~kg}$ for casting and/or hot rolling simulations compared to $100 \mathrm{t}$ and more for a single shot on the production unit. Also important parameters such as segregation indices or time-temperature - 
transformation diagrams can be determined by using lab - scale physical simulation tools and use of microstructural analysis methods. Moreover, important material parameters such as flow stress curves for hot and cold deformation can be determined with sufficient accuracy by combining measurement of rolling force and torque data acquisition and their combination with proper deformation models and inverse analysis. The acquisition of such data helps enormously in designing proper time-temperature-deformation paths for production facilities that obey constraints induced by given plant layouts and/ or safety precautions intended to prevent from cobbling and, hence, wasting valuable production time by scrap removal and unscheduled maintenance work.

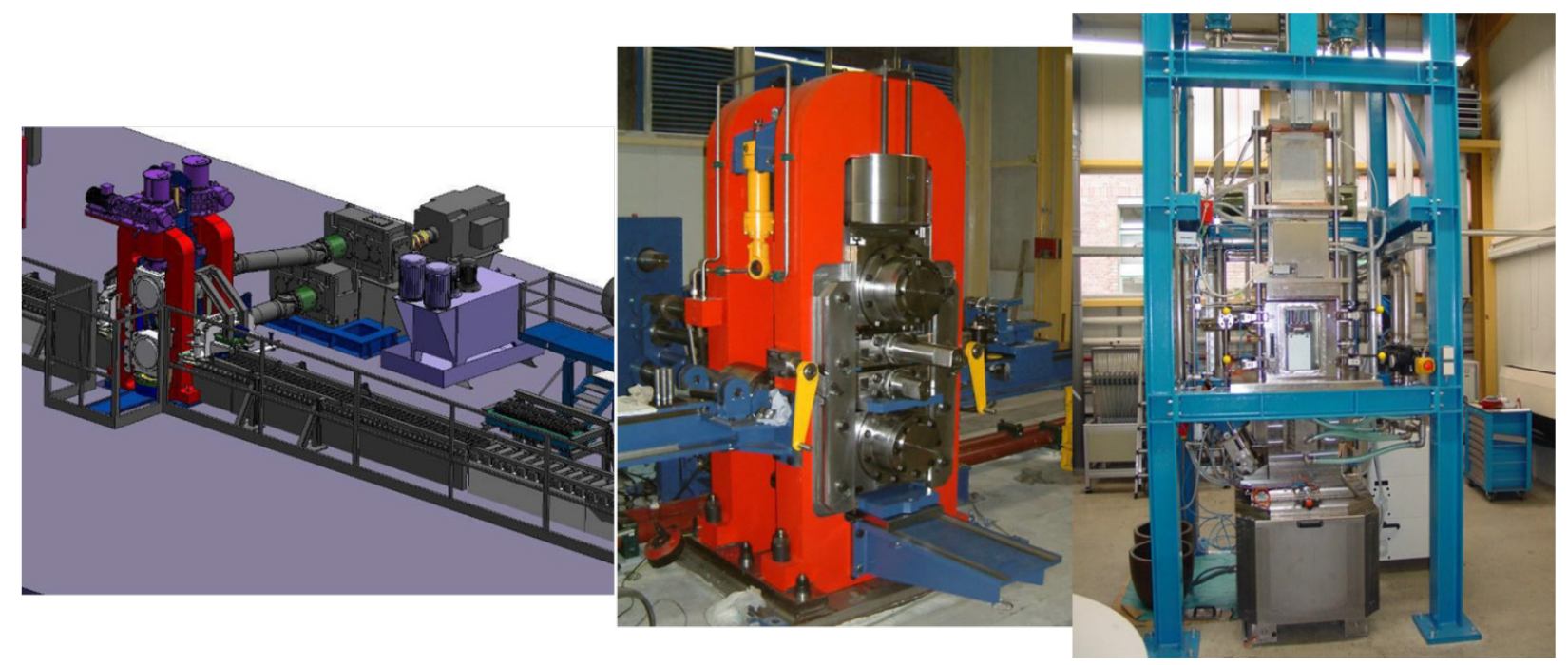

Fig. 3: Examples for simulators being used in product development at leading premium quality steel producers worldwide. Left: hot rolling simulator, middle: cold rolling simulator, right: galvanizing simulator (source: Primetals Technologies).

Another important point is the use of lab - data acquired as a feedback and validation means for processing models. Properly executed, such a data-analytics based feedback loop results in physics - based metallurgical models with a wide range of validity which can be used for upscaling data acquired in the lab to the large - scale situation in the production facility. This in turn lowers the probability for unexpected events when doing production trials.

Eventually, combining production plant data with metallurgical models gives feedback on the accuracy of the similarity laws used for upscaling from lab to production plant and eventually results in a highly valuable tool for simulation, what - if analysis, Know - How build up and training. However, it has to be pointed out that, in the case of rolling facilities, closing this final feedback loop necessitates the use of data acquisition systems that accomplish so - called segment based data collect ion such as the Through - process optimization system (TPO) including through process quality control (TPQC) functionality already installed at the HBIS facilities in the Tangshan - stainless steel and the Tangshan - THSAS complex [22][23]. To outline the position related data collection functionality of TPO Fig. 4 and Fig. 5 show the determination of boundary conditions experienced by a particular piece of rolled strip for the case of an endless strip production (ESP) plant. 


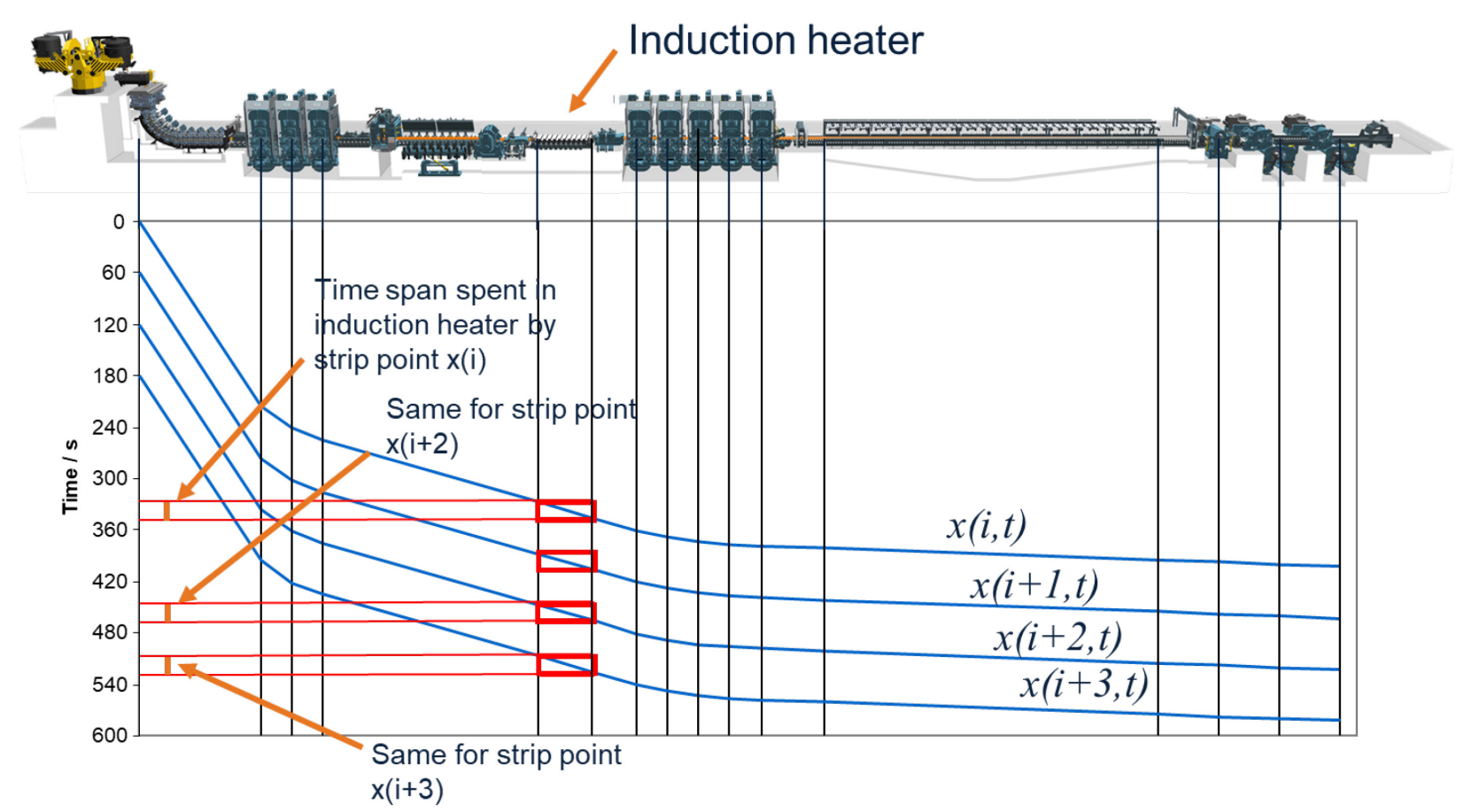

Fig. 4: Determination of segment position in plant as a function of the (later) strip head entering the casting mould at time $t=0$. Also shown is the position as a function of time for strip segments entering 60, 120, 180s after strip head entrance in the mould and constant speed. Indicated time span is interval when strip segment traverses induction heater.

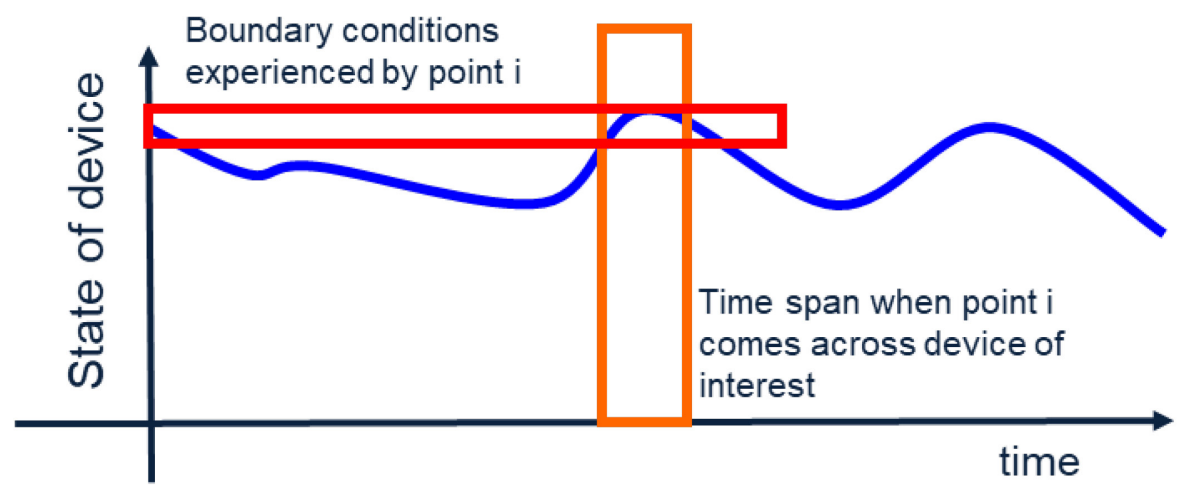

Fig. 5: Determination of boundary condition experienced by individual strip-segment $i$ in plant. The boundary condition applied by segment $i$ corresponds to the state of the device of interest when the strip segment passes by.

Having correspondingly mature numerical simulation tools in place, physical simulation systems (similar as shown in Fig. 3) as well as a TPO - type - system [22][23] the optimum approach for product development is the waterfall - type model with feedback to previous steps as displayed in Fig. 6. This approach ideally combines the thorough but still incomplete insight into material - plant interaction provided by several but relatively cheap numerical and small - scale physical simulations with a few large - scale production trials that give full insight in terms of plant - material interaction. Time to market is optimized by doing relatively coarse investigations to clarify the feasibility of new metallurgical designs and consecutive refinement of investigations for promising approaches. 


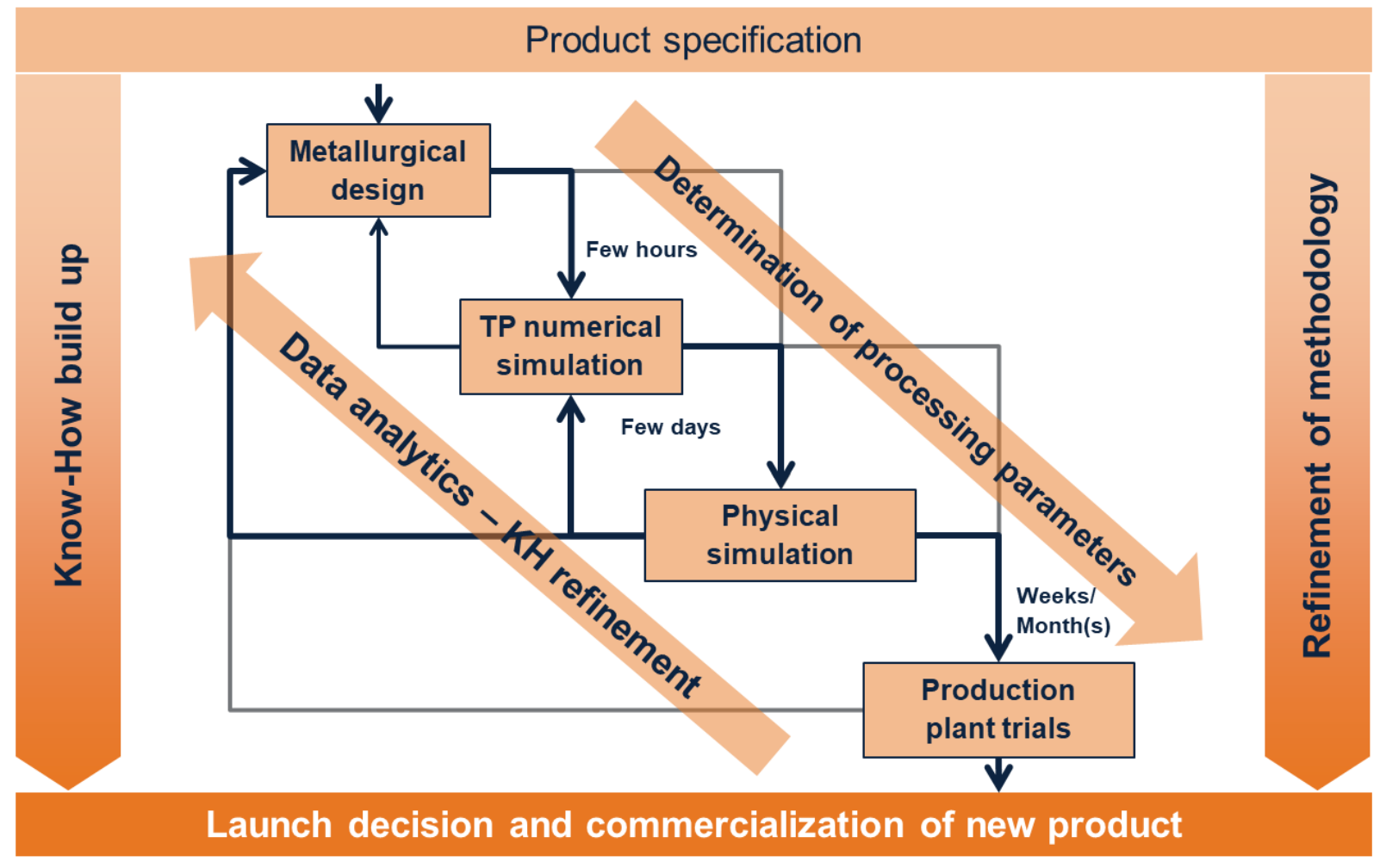

Fig. 6: Smart product development process. Demand on development time on production facilities, cycle time per iteration of product development, and time to market.

Also, the risk of plant shutdowns is minimized this way as the time for trial production is kept at a minimum by construction and safe processing parameters can be very reliably determined by a combination of numerical and physical simulations.

Besides this, lab - scale investigations and simulations using calibrated physical models increase the probability for successful trials dramatically compared to "shots into the blue".

Fig. 7 gives an indication on trial costs per hour for different steps in product development under the assumption of full capacity load for different facilities giving an indication on the difference in order of magnitude for numerical investigations, lab scale trials and full - size plant trials.

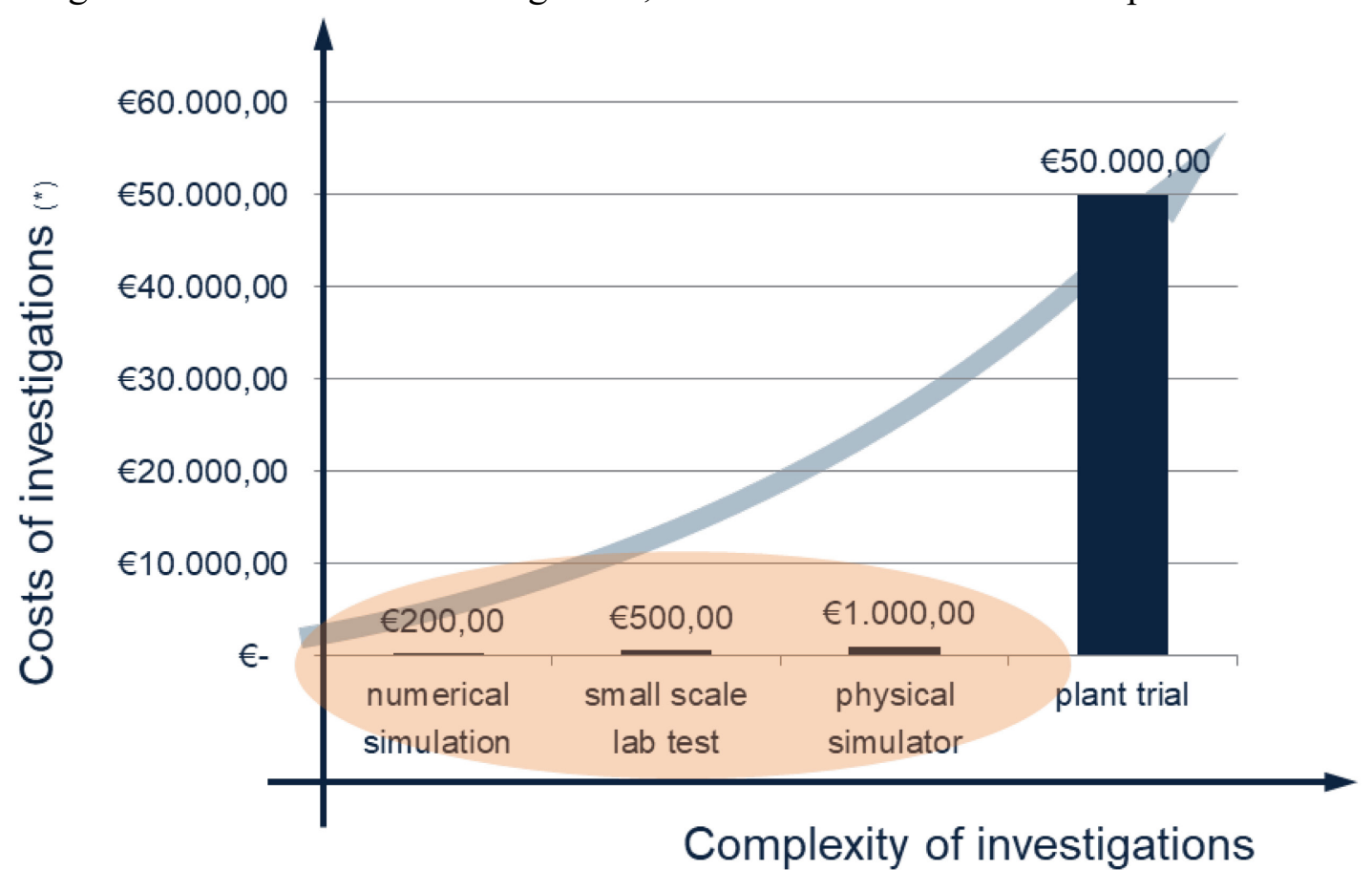

Fig. 7: Estimated costs per hour for product development steps of different scale. 


\section{Conclusions}

After the boom times induced by the post - world war II restructuring in the fifties and sixties of the last century in Europe and the emerging of the Chinese economy between 1995 and 2012 there is little hope that the world wide steel demand will increase in the near future as major drivers of growth such as industrialization of large markets and high growth rates of the world population are improbable for the next decades. Therefore the steel market will shift towards higher quality for customers at lower margins for suppliers. In order to secure or increase market shares steel producers will drive digitalization and service orientation including the establishment of new sales channels. Mainly driven by a decrease in the steel demand from construction industry and an overall shift of demand towards sectors demanding higher value add products in China.

As a consequence of strict environmental regulations pressure for innovation in the automotive industry will be high and transmitted to steel suppliers. Therefore, efficient product development will be of vital importance for steel producers struggling for market shares provided by increasingly complex and sensitive products. To account for this trend steel suppliers will evolve towards producing highly diversified premium products combining high strength and formability of the AHSS and UHSS types.

In view of product development dedicated approaches featuring short time to market, efficient Know - How build up and facilitation of increasing production plant utilization combined with minimum probability of trial - induced outages of production units at minimum development costs will be needed. A corresponding approach including numerical simulation of microstructure evolution, a multi - scale approach combining laboratory and production facility trials including feedback loops for continuous improvement of trial design and metallurgical modelling has been presented.

\section{References}

[1] RCG Research \& Consulting Group AG, SWITZERLAND, "Global trends in steel industry and steel markets: a look ahead”, International Steel Trade Day, Milano / 21 May, 2015,

[2] Sedov, I. Budanov, "Overview of steel and iron market”, Deloitte CIS Research Centre, Moscow, 2017, https://www2.deloitte.com/content/dam/Deloitte/ru/Documents/manufacturing/ overview-of-steel-iron-market-2017-eng.pdf

[3] J. E. Lichtenstein, R. Oppelt, "Five inconvenient truths for the global steel industry", natural resources blog, insights and opinions on the latest trends in mining, metals, forest products and building materials, Jan 26, 2017, https:/www.accenture.com/us-en/blogs/blogs-five-global-steelindustry

[4] Bekir Baris Ciftci, world steel association, "Global steel industry: outlook, challenges and opportunities", $5^{\text {th }}$ international steel industry $\&$ sector relations conference, April, $20^{\text {th }} 2017$, Istanbul

[5] J. E. Lichtenstein, "Insights and actions for managing disruption in the steel industry", natural resources blog, insights and opinions on the latest trends in mining, metals, forest products and building materials, Feb 28, 2017. https://www.accenture.com/us-en/blogs/blogs-actionsmanaging-disruption-steel-industry

[6] Prableen Bajpai, CFA (ICFAI), The World's Top 10 Economies, July 72017 , https://www.investopedia.com/articles/investing/022415/worlds-top-10-economies.asp, based on data of the IMF word economic outlook database, https://www.imf.org/external/pubs/ft/weo/2017/ 01/weodata/index.aspx 
[7] https://obamawhitehouse.archives.gov/the-press-office/2012/08/28/obama- administrationfinalizes- historic-545-mpg-fuel-efficiency-standard

[8] B. Smith, A. Spulber, S. Modi, T. Fiorelli, "Technology Roadmaps: Intelligent Mobility Technology, Materials and Manufacturing Processes, and Light Duty Vehicle Propulsion", the center for automotive research, Ann Arbor, Michigan, June 2017. http://www.cargroup.org/wpcontent/uploads/2017/07/Technology_Roadmaps.pdf

[9] P. Blain, "Steel perspectives for the automotive industry", OICA, International Organization of Motor Vehicle Manufacturers, May 31st 2012, https://www.oecd.org/industry/ind/50498824.pdf

[10] FutureSteelVehicle Results and Reports, world auto steel association, http:/www.worldautosteel.org/download_files/FutureSteelVehicle\%20Results\%20and\%20Reports/ FSV_Phase1_ExecutiveSummary.pdf

[11] https://www.worldsteel.org/steel-by-topic/steel-markets/automotive.html

[12] M. Wurth, D. Fairclough, V. Mella, ArcelorMittal, 2017 PREMIUM REVIEW CONFERENCE, 1. Dec 2017, p. 60, http://corporate.arcelormittal.com/ /media/Files/ A/ArcelorMittal/investors/presentations/investor-conference/2017/soc-gen-prenium-review-dec2017.pdf

[13] M. C. Valigi, M. Rinchi, "Chattering in rolling of advanced high strength steels", in "Rolling of Advanced High Strength Steels: Theory, Simulation and Practice", Ch. 13, Ed. By J. Zhao, Z. Jiang, CRC Press, 2017, ISBN 978-1-4987-3031-0.

[14] B. C. De Cooman, " $3{ }^{\text {rd }}$ generation AHSS concepts for body in white", Bad Neuheim, P.31.

[15] M. Soliman, H. Palkowski, "Hot rolling practice of multiphase steels", in "Rolling of Advanced High Strength Steels: Theory, Simulation and Practice", Ch. 13, Ed. by J. Zhao, Z. Jiang, CRC Press, 2017, ISBN 978-1-4987-3031-0.

[16] E. H. Atzema, "Formability of auto components" in "Automotive Steels: Design, Metallurgy, Processing and Applications", Ch. 3, p. 47, Ed. by R. Rana, S. Sing, Woodhead publishing,

[17] A. Abraham, "Metallic material trends in the north American light vehicle", great designs in steel seminar, Livonia MI, May 13 (2015)

[18] H. Cho, M.-K. Kong, "The Steel Industry over the next two decades", Asian steel watch, p. 38-45, Vol. 03, June 2017, https:/www.posri.re.kr/files/file_pdf/59/334/6794/ 59_334_6794_file_pdf_1499150181.pdf

[19] A. Chalabyan, L. Mori, S. Vercammen, "The current capacity shake-up in steel and how the industry is adapting", Metals and mining practice, McKinsey \& Company, Jan. 2018, https://www.mckinsey.com/ /media/McKinsey/Industries/Metals\%20and\%20Mining/Our\%20Insig hts/The $\% 20$ current $\% 20$ capacity $\% 20$ shake $\% 20$ up $\% 20$ in $\% 20$ steel $\% 20$ and $\% 20$ how $\% 20$ the $\% 20$ indust ry\%20is\%20adapting/The-current-capacity-shake-up-in-steel-and-how-the-industry-is-adapting.ashx

[20] M. Wurth, D. Fairclough, V. Mella, ArcelorMittal, 2017 PREMIUM REVIEW CONFERENCE, 1. Dec 2017, p. 33-34, http://corporate.arcelormittal.com/ /media/Files/A/Arcelor Mittal/investors/presentations/investor-conference/2017/soc-gen-prenium-review-dec-2017.pdf

[21] Automotive standard TS16949.

[22] G. Kurka, G. Hohenbichler, TPQC - Through-Process Quality Control, 9th International Steel Congress, CISA, Beijing, May 2016 
[23] J. F. Plaul, W. Oberaigner, Y. Zhai, T. Pfatschbacher, M. Kuegel, "Through-Process Optimization (TPO), an integrated solution for steel production with best quality and highest productivity at lowest cost", 10th International Steel Congress, CISA, Beijing, May 2018, to be published.

[24] A. Jungbauer, B. Linzer, A. Viehböck, "Thin is beautiful -ESP to further develop the cold band substitute market", Proceedings of the METEC \& $2^{\text {nd }}$ ESTAD conference, 15-19 June 2015, Düsseldorf, Germany.

[25] S. Bragin, S. Grosseiber, B. Linzer, A. Rimnac, "Endless production of multiphase steels", Proceedings of the $10^{\text {th }}$ international and $7^{\text {th }}$ European rolling conference, 6.-9.6.2016, Graz 